\title{
Sunlight-driven water splitting using hematite nanorod photoelectrodes
}

\author{
FLAVIO L. SOUZA \\ Laboratory of Alternative Energy and Nanomaterials (LEAN), Universidade Federal do ABC/ \\ UFABC, Avenida dos Estados, 5001, 09210-580 Santo André, SP, Brazil
}

Manuscript received on July 27, 2017; accepted for publication on September 6, 2017

\begin{abstract}
The efficiency of nanostructures for photoelectrochemical water-splitting is fundamentally governed by the capability of the surface to sustain the reaction without electron trapping or recombination by photogenerated holes. This brief review will summarize the latest progress on hematite, designed with columnar morphology via chemical synthesis, for photoelectrochemical cell application. The columnar morphology efficiently minimizes the number of defects, grain boundaries, and surface traps normally present on the planar morphology. The major drawback related to hole diffusion through the solid/liquid interface was addressed by using high annealing temperature combined with dopant addition. A critical view and depth of understanding of these two parameters were discussed focusing on the molecular oxygen evolution mechanism from the sunlight-driven water oxidation reaction.
\end{abstract}

Key words: sunlight irradiation, water oxidation reaction, photoanode, hematite, columnar morphology.

\section{INTRODUCTION}

The global demand for energy remains based on fossil fuel consumption, which has generated significant emissions of $\mathrm{CO}_{2}$ into the atmosphere over decades. Considering the pace at which technology and populations grow worldwide, a drastic enhancement in energy consumption could be predicted soon (Lewis and Nocera 2006). Identifying novel technology to provide clean and renewable energy sources that supply the global demand and reduce harmful emissions is an urgent step towards the realization of a sustainable, carbon-

\footnotetext{
E-mail: flavio.souza@ufabc.edu.br

* Contribution to the centenary of the Brazilian Academy of Sciences.
}

neutral society (Landman et al. 2017). Among alternative sources of energy, the hydrogen fuel generated by a sunlight-driven water splitting process might lead to a relatively inexpensive and clean method for large-scale production (Bolton and Hall 1979, Bard and Fox 1995). Engineering of artificial photosynthetic systems based on earth-abundant elements that enable the efficient conversion of solar photons into chemical energy by splitting $\mathrm{H}_{2} \mathrm{O}$ into $\mathrm{H}_{2}$ and $\mathrm{O}_{2}$ molecules could lead to economical industrial production. Several review papers and books addressing the progress achieved in nanomaterial design and performance as photoelectrodes for sunlight conversion into chemical energy via a water-splitting process have been published (Graetzel 1981, Sivula et al. 2011, Hamann 2012, Bora et al. 2013, de Carvalho and 
Souza 2014, Hisatomi et al. 2014, Su and Vayssieres 2016, Kment et al. 2017). This review will cover the fundamental aspects of the photoelectrochemical (PEC) cell, focusing on hematite with onedimensional morphology designed by a templatefree low-temperature chemical approach using a simple apparatus, by the Purpose-Built Materials (PBM) method (Vayssieres et al. 2000, 2001a). This methodology has gained attention due to the simplicity and flexibility of synthesizing a broad range of materials in powder and film form simultaneously, including active materials for direct-solar-conversion-to-hydrogen fuel. The fundamental aspects of PEC cell operation and semiconductor requirements will be described to provide an overview of the working principle of the chemical reactions. The design concept of hematite $\left(\alpha-\mathrm{Fe}_{2} \mathrm{O}_{3}\right)$ nanostructure via the PBM process, and the latest advances regarding its application in PEC cell will be discussed. Finally, the technical and scientific issues that limit hematite from achieving commercial application will be explored. Much research has been dedicated to this field, and readers are encouraged to consult the references cited in accordance with their interest.

\section{PEC-SEMICONDUCTOR BASED OPERATION AND REQUIREMENTS}

The PEC and photocatalytic (PC) cells have been demonstrated as cleaner, less expensive, robust routes for efficient hydrogen production that involve the use of abundant elements (metal oxides semiconductors), water, and solar photons. The sunlight-driven water splitting process via PEC or PC cells is often referred as an artificial photosynthesis and accomplishing the realistic development of this methodology is highly prioritized in chemistry (Graetzel 1981, Bard and Fox 1995). The operation of PC devices involves the generation of gaseous hydrogen and oxygen by a photocatalyst material dispersed in pure water (Figure 1a). The PEC cell is based on photoactive electrodes that operate similarly to the conventional electrolysis system, where the $\mathrm{O}_{2}$ reaction occurs at the anode and $\mathrm{H}_{2}$ is evolved at the cathode in the presence of an electrolyte that completes the electrical current loop (Figure 1b). The tremendous advantage of the PEC cell is the possibility of generating spatially-separated $\mathrm{H}_{2}$ and $\mathrm{O}_{2}$ to allow facile collection. In PEC cell operation one or both electrodes must be a semiconductor that absorbs solar irradiation, and a space-charge (depletion) layer is formed at the semiconductor/ liquid junction (SCLJ). In the case of PEC cells using an n-type semiconductor as a photoanode, after sunlight absorption a pair of electron-holes is generated and separated by the space-charge layer. The ideal scenario is represented by the schematic diagram in Figure 1c, which shows four fundamental steps: (1) light absorption, (2) charge separation, (3) charge injection to the back contact (for reducing water at the cathode surface), and (4) hole diffusion to the electrode-electrolyte interface to oxidize water (Sivula 2013, Zandi and Hamann 2015, Soares et al. 2016). In summary, the minority carriers (holes, $\mathrm{h}^{+}$) are injected into the SCLJ interface to promote the water oxidation reaction (OER) and release the $\mathrm{O}_{2}$ molecule. The majority carriers $\left(\mathrm{e}^{-}\right)$are collected by the substrate travelling through the external circuit to reach the cathode surface (normally platinum foil) and promote the other half of the reaction to release $\mathrm{H}_{2}$.

The chemical reaction that occurs in both electrodes and represented in Fig. 1b can be described by the following equation:

Cathode: $2 \mathrm{H}^{+}+2 \mathrm{e}^{-} \rightarrow+\mathrm{H}_{2} \mathrm{E}_{\text {red }}^{\mathrm{o}}=0 \mathrm{~V}$

Photoanode: $2 \mathrm{H}_{2} \mathrm{O}+4 \mathrm{~h}^{+} \rightarrow+\mathrm{O}_{2}+4 \mathrm{H}^{+} \mathrm{E}_{\mathrm{oxi}}^{\mathrm{o}}=1.23 \mathrm{~V}$ (2).

The water-splitting process requires a minimum voltage and according to the Nernst equation and chemical reaction above this value 
a)

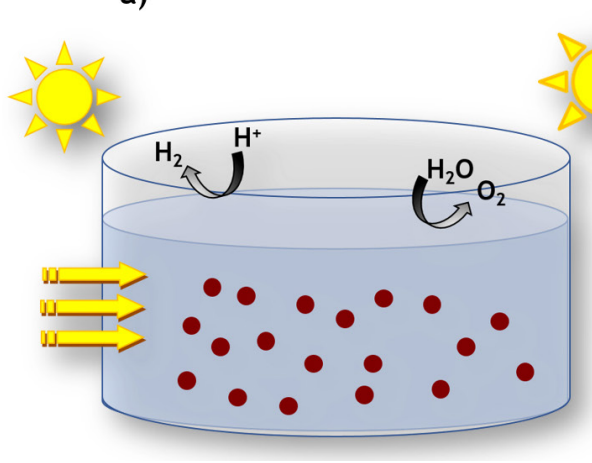

b)

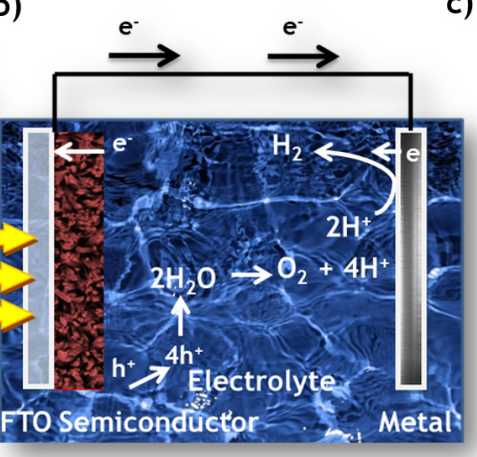

c)

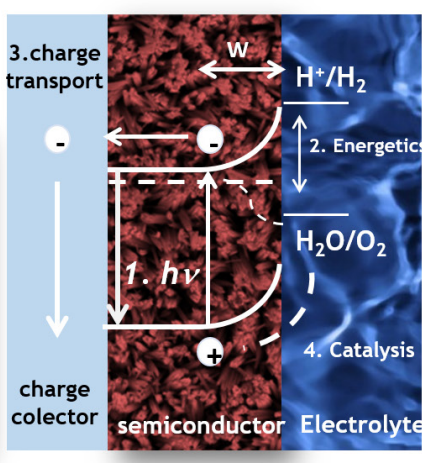

Figure 1 - a) Schematic representation of photocatalytic (PC) cell, b) Scheme of photoelectrochemical (PEC) cell operation, and c) N-type semiconductor (photoanode) operation under sunlight irradiation.

corresponds to $1.23 \mathrm{~V}$ per electron transferred (Trasatti 1980, Graetzel 1981, Nozik and Memming 1996, Walter et al. 2010). From fundamental thermodynamic concepts given the free Gibbs energy under standard conditions, 237.2 $\mathrm{KJ} / \mathrm{mol}$ of energy is necessary to split one water molecule into $\mathrm{H}_{2}$ and $1 / 2 \mathrm{O}_{2}$. Therefore, an n-type semiconductor to promote the OER must absorb photons with energy values equal to or larger than the thermodynamic prediction. However, the total energy loss related to the experimental condition (such as electrode contacts) might increase this energy need to a higher value than the theoretical prediction (Sivula et al. 2011, Hamann 2012, Sivula 2013). The selection of semiconductor materials that meet most of the requirements for PEC application has been a crucial factor in boosting the device efficiency and development. The ideal semiconductor must have a valence $\left(\mathrm{E}_{\mathrm{vb}}\right)$ and conduction $\left(\mathrm{E}_{\mathrm{cb}}\right)$ band edge position in an energy range that matches the electrochemical potential, $\mathrm{E}^{\circ}$, of $\left[\left(\mathrm{H}^{+} / \mathrm{H}_{2}\right)\right.$ and $\left.\left(\mathrm{O}_{2} / \mathrm{H}_{2} \mathrm{O}\right)\right]$ to drive the water oxidation (OER) and reduction (HER) reactions under sunlight irradiation by using the photogenerated hole/electron pair charge. The diagram on Figure 2a exhibits the most common semiconductors investigated and the band edge position at $\mathrm{pH}=0$ against the vacuum and normal standard hydrogen (NHE) electrode, as references.
While semiconductors completely drive the water splitting reaction under illumination (such as $\mathrm{ZnO}$, $\mathrm{TiO}_{2}$, and $\mathrm{SrTiO}_{3}$ ), a few fundamental aspects limit their efficiency in the PEC device. These three oxides have a wide band gap energy that allows them to absorb a small fraction of the visible light, which compromises the performance since the $95 \%$ of the sunlight irradiation on Earth is in the visible range. This low absorption rate can be overcome by choosing a different material able to absorb most of the visible sunlight spectrum (see diagram Figure 2a). In general, the photoinduced water splitting reaction must be conducted free from charge recombination at the semiconductorliquid interface. The losses during charge separation processes at the solid-liquid interfaces are related to a slow kinetics and the necessity of an overpotential to drive the chemical reactions (OER and HER), which increases the challenge of finding a good photoelectrode candidate. The losses at a semiconductor-liquid interface and the effects on the overall performance during the photoelectrolysis process have been addressed in previous review papers (Sivula et al. 2011, Hamann 2012, Sivula 2013, Tamirat et al. 2016, Zhang et al. 2017). Therefore, the selection of a semiconductor might be made considering these losses, which requires an energy of 1.6-2.4 eV per electron-hole pair generated to promote the chemical reactions 
(OER and HER) induced by light. It is essential to understand the thermodynamic, kinetics, and physical parameters of the solid-liquid interface and the electrocatalyst surface to develop efficient photoelectrochemical devices based on semiconductor technology. The fundamental knowledge of the physics of semiconductor will not be addressed in this review, but can be found in the literature (Nozik and Memming 1996, Yang et al. 2014).

The pioneering work on sunlight-induced water splitting using n-type semiconductors $\left(\mathrm{TiO}_{2}\right)$ as photoelectrodes was performed by Fujishima and Honda, who achieved a modest performance (Fujishima and Honda 1972). Since this seminal
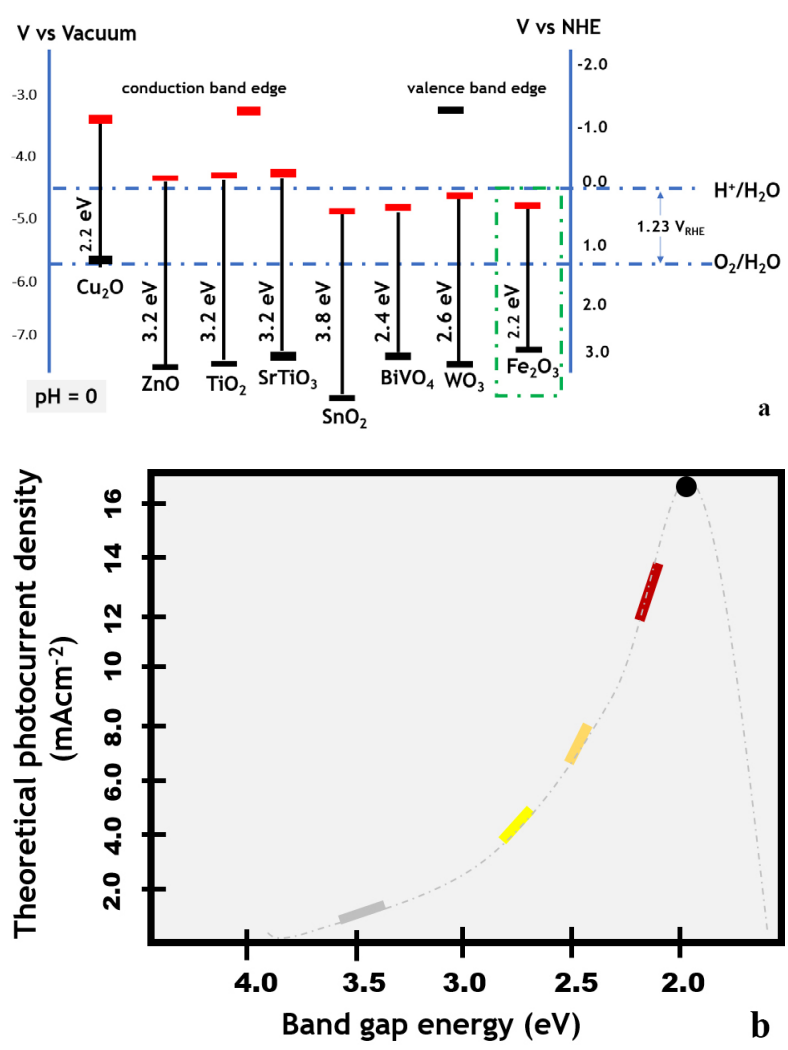

Figure 2 - (a) Diagram of semiconductor valence and conduction band edge position against the electrochemical potential of $\mathrm{H}_{2}$ and $\mathrm{O}_{2}$ molecule formation at $\mathrm{pH}=0$, relative to vacuum and normal standard hydrogen electrode references; (b) Maximum theoretical photocurrent density according to the semiconductor band gap energy: $\mathrm{SrTiO}_{3}$ (gray), $\mathrm{WO}_{3}$ (light yellow), $\mathrm{BiVO}_{4}$ (intense yellow) and $\mathrm{Fe}_{2} \mathrm{O}_{3}$ (intense red). study, the ideal material for this purpose has been pursued. Figure $2 \mathrm{~b}$ exhibits some of the most promising photoanodes for PEC application based on a theoretical maximum efficiency varying from 2.0-12 mA.cm ${ }^{-2}$ under sunlight irradiation (at 1.23 $\mathrm{V}_{\mathrm{RHE}}$ ). The color of the solid traces indicates the band gap energy, e.g., $\mathrm{SrTiO}_{3}$ (gray), $\mathrm{WO}_{3}$ (light yellow), $\mathrm{BiVO}_{4}$ (intense yellow) and $\mathrm{Fe}_{2} \mathrm{O}_{3}$ (intense red). These n-type semiconductors associated with the nanoscale morphology control have shown a good performance for water oxidation induced by sunlight irradiation. $\mathrm{SrTiO}_{3}$ was heavily investigated due to the high chemical and photochemical stability, the wide band gap energy (at $3.2 \mathrm{eV}$ ) favorable for photocatalysis application, and a low overpotential demand (Mavroides et al. 1976, Nozik 1978, Kudo and Miseki 2009). To boost the efficiency as a photoanode in PEC, several strategies have been employed such as surface modification with quantum dots and direct doping (Hisatomi et al. 2014, Pinheiro et al. 2014). Some progress was achieved by dopant insertion and morphology control, but the absorption coefficient was low which limited the maximum theoretical photocurrent response to $2 \mathrm{~mA} \cdot \mathrm{cm}^{-2}$ (Figure 2b) and remains a challenge for the use of this material as a photoanode in the PEC cell. Alternatively, tungsten oxide $\left(\mathrm{WO}_{3}\right)$ is a stable photoanode but can theoretically provide a maximum of solar-tohydrogen conversion near 8\% (Dias et al. 2016). This limited efficiency is associated with the large band gap energy at $2.7 \mathrm{eV}$ that gives conduction band edges that are energetically insufficient to reduce water with expected kinetic losses (Santato et al. 2001, Liu et al. 2011, Goncalves et al. 2012, Kafizas et al. 2017, Li et al. 2017a). Bismuth vanadate $\left(\mathrm{BiVO}_{4}\right)$ has also become a promising n-type photoanode (represented by the solid, intense yellow line, Figure $2 b$ ) due a band gap energy near $2.4 \mathrm{eV}$ that allows a theoretical solar-to-hydrogen conversion efficiency ( $\eta \mathrm{STH})$ approaching 9.2\% (Sayama et al. 2003, Park et al. 
2013, Sivula and Van De Krol 2016, Choi et al. 2017). This prediction corresponds to a maximum photocurrent density value close to $7.5 \mathrm{~mA} . \mathrm{cm}^{-2}$ under visible light. However, the efficiency reported with $\mathrm{BiVO}_{4}$-based photoanodes is far below the values expected. The reason behind of the poor performance is associated with drawbacks such as excessive electron-hole recombination of approximately 60-80\% due slow electron transport and poor water oxidation kinetics (Sivula and Van De Krol 2016).

Hematite becomes apparent as the most investigated, efficient, and promising photoanodebased material for PEC application with a maximum solar-to-hydrogen conversion efficiency $(\eta \mathrm{STH})$ theoretically predicted around $16 \%$, which corresponds to $12 \mathrm{~mA} . \mathrm{cm}^{-2}$ in photocurrent density under sunlight irradiation (red line, Figure 2b) (Murphy et al. 2006, Walter et al. 2010, Hamann 2012, Sivula 2013). Although substantial progress has been made, important drawbacks have prevented the development of this technology using hematite. Hardee and Bard first reported hematite as a promising photoanode material for water splitting in 1976 by showing the capability for absorbing solar spectra (visible range) and stability under anodic potential (Hardee and Bard 1976). For that study, thin films of $\mathrm{Fe}_{2} \mathrm{O}_{3}$ were grown onto $\mathrm{Ti}$ and $\mathrm{Pt}$ substrates by chemical vapor deposition (CVD) and the photoelectrochemical measurement was conducted under a selected light wavelength $(500 \mathrm{~nm})$ and bias at $+0.8 \mathrm{~V}$ (saturated calomel electrode, as reference) to reveal a modest performance. Quinn et al. later showed that single crystals increased efficiencies around $20 \%$ at a lower potential of $+0.5 \mathrm{~V}$ (saturated calomel electrode, as reference) when illuminated at 475 nm (Quinn et al. 1976). Kennedy et al. doped an n-type hematite photoanode with different ions such as $\mathrm{Si}^{4+}, \mathrm{Sn}^{4+}, \mathrm{Ge}^{4+}$, and $\mathrm{Ti}^{4+}$ to show an enhanced performance compared with the undoped one (Kennedy and Frese 1978, Shinar and Kennedy
1982). No significant efforts were observed until the important breakthrough associated with the morphology design.

The advent of nanotechnology provided a fresh perspective and an alternative way to boost the performance of photoanode-based on transition metal oxides (TMOs) through nanostructure design (Hagfeldt and Graetzel 1995). The development of controlled morphology regarding shape, size, surface, and material doping enabled an improved photogenerated charge-separation, which could facilitate the hole diffusion through the SCLJ and electron injection to the back contact (transparent conductor substrate, TCO). In the following section, we will focus on the nanoscale improvements to the hematite-based photoanode synthesized by a lowcost and facile scalable chemical method (Purpose Built Materials, PBM), which has gained much attention in the last five years.

\section{HEMATITE PHOTOANODE}

Iron is the fourth most common element in the earth's crust composition, which combined with several fundamental characteristics make this widespread mineral attractive for many technological applications including catalysis, optoelectronics, and sensors (Xavier et al. 2014, Wang et al. 2015b, Bailly et al. 2016, Landman et al. 2017). It is commonly found in nature in oxide form with four different crystallographic arrangements (such as alpha, beta gamma, and epsilon) (Navrotsky et al. 2008, Lavina and Meng 2015, Tuček et al. 2015). These polymorphic phases have been intensively explored from a scientific and commercial viewpoint. Hematite $\left(\alpha-\mathrm{Fe}_{2} \mathrm{O}_{3}\right)$ is the most common iron oxide polymorph, with a rhombohedral crystallographic arrangement (corundum-type) (Pauling and Hendricks 1925, Smith and Fuller 1967, Eggleston 2008). The unit cell belongs to the space group $\mathrm{R} 3 \mathrm{C}$, where the $\mathrm{O}_{2}^{-}$atoms form a close-packed hexagonal lattice 
along the [001] direction with the octahedral interstices occupied by $\mathrm{F}^{3+}$ in the (001) basal plane. The hematite unit cell is composed by $\mathrm{FeO}_{6}$ pairs forming dimers of $\mathrm{Fe}_{2} \mathrm{O}_{9}$ that exhibit a structural arrangement along the c-axis (Sivula et al. 2010). It's worth to note that only two-thirds of the available octahedral interstices are filled with $\mathrm{Fe}^{3+}$. The structural arrangement and chemical bond distance of $\mathrm{Fe}-\mathrm{O}$ has been discussed by Pailhé et al. The repulsion effect and structural distortion are due to the shorter cation distance $\left(\mathrm{Fe}^{3+}-\mathrm{Fe}^{3+}\right)$ and can be minimized by successive thermal treatment or crystal growth that relax the overall structure and maximizes the distance between the two cations in the $\mathrm{Fe}_{2} \mathrm{O}_{9}$ dimers (Pailhé et al. 2008). This structural distortion of hematite unit cells is frequently revisited to explain the origin of the significant changes to the optical properties that are commonly observed for this material. Regarding the optical characteristic of hematite, it is noted that the presence of a direct (at $\mathrm{eV}$ ) and indirect $(\mathrm{eV})$ electronic transition gives a red-color aspect and enables the absorption of a wide range of the electromagnetic spectra. The direct transition that corresponds to the absorption at $400 \mathrm{~nm}$ is attributed to the electronic transition between $2 p$ orbitals of nonbonding $\mathrm{O}$ to the $\mathrm{d}$ orbital of $\mathrm{Fe}^{3+}$. The indirect transition that gives the absorption band observed at $590 \mathrm{~nm}$ is associated with an electronic transition between the d-d orbitals of $\mathrm{Fe}^{3+}$ from the valence to the conduction band. This classical explanation drives the comprehension of the optical properties of hematite. The choice of methods to manufacture semiconductor material profoundly influences the light absorption by shifting the band gap energy to different degrees of structural disorder. In general, the experimental data are commonly analyzed for a semiconductor material using the equation below:

$(\alpha h v)^{\mathrm{n}}=\mathrm{B}\left(\mathrm{h} v-\mathrm{E}_{\mathrm{g}}\right)$

where $\alpha$ is the absorption coefficient, $\mathrm{B}$ is a materialdependent constant, hn is the incident light energy,
$\mathrm{E}_{\mathrm{g}}$ is the optical bandgap energy, and the constant $\mathrm{n}=1 / 2,2$ for indirect and direct transitions, respectively (Duret and Grätzel 2005). For several different morphologies on the nanometric scale, the normal value of band gap energy reported for hematite is around 1.9-2.2 eV (Souza et al. 2009a, b). This range of band gap enables absorption of a large fraction of the solar spectrum and indicates a promising candidate for PEC application. For instance, considering that the $95 \%$ of the incident solar spectrum on Earth is in the visible range and the relationship below describes the fraction of photons absorbed (Lothian 1963):

$\mathrm{f}=1-\mathrm{e}^{\mathrm{\alpha l}}$ (neglecting reflectance)

where $\mathrm{f}$ is the fraction of real photon absorption, $\alpha$ is the absorption coefficient, and 1 is the optical path length. A designed hematite electrode with $400 \mathrm{~nm}$ of thickness enabled absorption of the total incident solar photons on Earth. This characteristic fulfills an important requirement for application as a photoelectrode in PEC devices.

Regarding the electronic properties of this corundum structure, the electron mobility is explained by taking the alternation in the valence state $\left(\mathrm{Fe}^{2+/ 3+}\right)$ into account; the electron transference occurs through $\mathrm{Fe}$ atoms following an electron hopping mechanism. Several experimental investigations have shown that the electronic conductivity can be substantially enhanced by three or four orders of magnitude through the $\mathrm{O}_{2}$ basal plane in the [001] direction. This anisotropic effect in the electron mobility on hematite has been the topic of many theoretical and experimental reports (Benjelloun et al. 1984, Rosso et al. 2003).

These fundamental characteristics of hematite including (i) earth abundance, (ii) narrow band gap enabling wide solar range absorption, (iii) excellent alkaline stability, and (iv) low-or nontoxicity has emerged over the last decade as promising photoanode for PEC cell application 
(Hamann 2012, Sivula 2013, Shen 2014, Su and Vayssieres 2016). Combining the properties with the morphology design in nanoscale will probably enable this material to achieve the predicted $16 \%$ of incident solar photons-to-hydrogen ( $\eta \mathrm{STH})$ conversion (Sivula et al. 2011). While hematite fulfills several key criteria to achieve stable and cost-effective commercial devices, the overall solar conversion efficiency is far from the theoretical prediction (Figure 2b). The limitations dictating this low performance are associated with poor optoelectronic properties such as: (i) a thicker film $(400 \mathrm{~nm})$ requirement for efficient light absorption, (ii) extremely poor electronic conductivity, (iii) a short hole diffusion length $(2-4 \mathrm{~nm})$ through the SCLJ, and (v) a large overpotential required for water oxidation associated with the kinetic losses (Walter et al. 2010, Sivula et al. 2011, Cho et al. 2016). The recombination losses and limitations may be harder to be overcome because hematite electrodes are characterized by deposition of polycrystalline material, contrary to the common semiconductor technology that is single-crystal based. This polycrystalline hematite layer exhibits complex characteristics that can be summarized as follows: (i) non-uniform grain sizes, (ii) a columnar structure, (iii) porosity, (iv) impurity segregation, and (v) grain-grain miss orientation that forms homo-junctions and hetero-junctions. As a consequence of this complex structure, three different electron/hole recombination pathways through the bulk are commonly observed on hematite electrodes: (i) two at the solid-solid junction and (ii) one at solid-liquid interface (Sivula et al. 2011, Cho et al. 2016). Losses associated with the solid-solid interfaces are due to: (1) hematite layer - transparent conductive glass substrate, and (2) through the hematite-hematite crystals or grain boundaries (Warren et al. 2013). Loss associated with the solid-liquid interface (SCLJ) is due to (3) the surface states and traps delay the hole transfer from the valence band through the semiconductor surface to react with the electrolyte. (Bertoluzzi and Bisquert 2012, Barroso et al. 2012, Young et al. 2013, Nellist et al. 2016).

The high recombination rate of bulk hematite affects the photogenerated charge separation efficiency and hinders the PEC performance. An impressive effort has been dedicated to designing nanostructured hematite photoelectrodes with different morphologies and incorporating donor elements ( $\mathrm{Ti}, \mathrm{Sn}, \mathrm{Co}, \mathrm{Mn}$ ) to minimize the losses associated with recombination pathways (Sivula et al. 2010, Gonçalves et al. 2011, Klahr and Hamann 2011, Kronawitter et al. 2011, de Carvalho et al. 2012, Ferraz et al. 2012, Kronawitter et al. 2012, Shen et al. 2012, 2013a, 2014c, Chiam et al. 2014, Ling and Li 2014). The morphology control at a nanometric scale leads to shortening of the hole diffusion distance to the semiconductor-liquid interface that may decrease the recombination rate. The incorporation of donor elements as an underor overlayer on a hematite electrode has minimized the recombination losses due to: (i) improving the electron injection efficiency through the TCO (underlayer) and (ii) enhancing the semiconductor surface for chemical reactions due to the addition of a passivating layer (overlayer), which reduces the surface traps (Steier et al. 2014, Tamirat et al. 2016, Shinde et al. 2015, Nellist et al. 2016). Another common strategy used to prevent surface traps and reduce the electron-hole recombination on hematite is surface etching (Shinde et al. 2016).

Therefore, the development of highperformance hematite photoanodes is strongly dependent on the synthetic process (deposition technique). It is essential to have a deep understanding and control of the nanostructure design to master water-splitting technology via a photoelectrochemical process. The hematite photoanode designed by a chemical method, such as colloidal deposition and the aqueous solution hydrothermal-assisted process gained much attention due to the highest performance achieved 
among those of physical and other reported methods. The following discussion will be conducted based on the latest advances in PEC performance by hematite photoanodes manufactured by an aqueous solution hydrothermal-assisted process, termed the Purpose-Built Material (PBM method) (Vayssieres et al. 2001a, b, Vayssieres 2004).

\section{HYDROTHERMAL-ASSISTED SYNTHESIS}

The latest advances on hematite n-type photoanode are related to the nanoarchitecture designing that provide active materials for direct solar photon conversion into chemical energy (hydrogen and oxygen molecule). Vayssieres et al. (2001a) brought a novel concept to the field of photoanode architecture in 2001 by introducing a one-step chemical process to grow hematite with nanorod/ wire morphology based on the interfacial tension control (surface free energy) using the Gibbs adsorption equation model (Vayssieres et al. 2001a). Minimizing the interfacial tension by leading the system stabilization of metal oxide might be possible by controlling the kinetics and thermodynamics of nucleation, growth, and the aging process. Such control enabled Vayssieres et al. (2001a) to propose a novel and simple way to synthesize one-dimensional morphology material, which consisted of a preparation of a precursor solution of metal salts or complexes with a specific ionic $\mathrm{pH}$ and ionic strength deposited onto various substrates (Vayssieres et al. 2000, 2001a). Figure 3 shows a short description and illustration of the apparatus with the procedure to prepare metal oxide materials with the anisotropic morphology. Once the precursor solution is prepared, commercial substrates (ex. FTO, ITO) are added in a closed autoclavable bottle and the solution is subjected to a temperature of $90-100{ }^{\circ} \mathrm{C}$ at different times. Later, a yellow layer is observed to homogeneously cover the substrate (identified as oxyhydroxide phase, by X-ray technique) and it became red after thermal decomposition due the annealing process (hematite phase). The layer thickness or nanometric dimensions (rod/wire length or diameter) were strictly controlled by the synthesis time (formation of the yellow layer) and an additional annealing process (red layer-substrate) represented in Figure 3. The scanning electron microscopy image (SEM) on the left side of the red-layer substrate shows an example of the morphology obtained by this PBM method, which illustrates formation of a welldistributed nanorod/wire over the substrate. The additional annealing process is needed to promote the thermal decomposition from the oxyhydroxide phase to the desired hematite phase in this case, but it has no influence on the morphology formation. Usually, this annealing treatment increases the wire/rod dimensions.

Vayssieres et al. 2002 (Lindgren et al. 2002, Beermann et al. 2000) used the PBM method to design vertical-aligned hematite nanorod electrodes and carried out a systematic photoelectrochemical investigation, evaluating several parameters (morphology, film thickness, electrolyte composition, and dye sensitization) and the influence on overall performance. The electrode response was discussed regarding incident-tophoto conversion efficiency (IPCE) showing an improvement 100-7 times better compared with electrodes composed by spherical morphology (Figure 4a) that were investigated earlier (Lindgren et al. 2002, Beermann et al. 2000). The nanorod morphology exhibited superior performance against spherical particles by varying the electrolyte $\mathrm{pH}$ from 6.8 to 12 , and even the sunlight irradiation was conducted through the electrolyte or electrode (front or back side).

The better performance showed by the vertical hematite nanorod electrode was associated with a more efficient electron transport through the back contact (substrate) due to a quasi-crystal morphology where a reduced number of grain boundaries and trapping sites are expected 


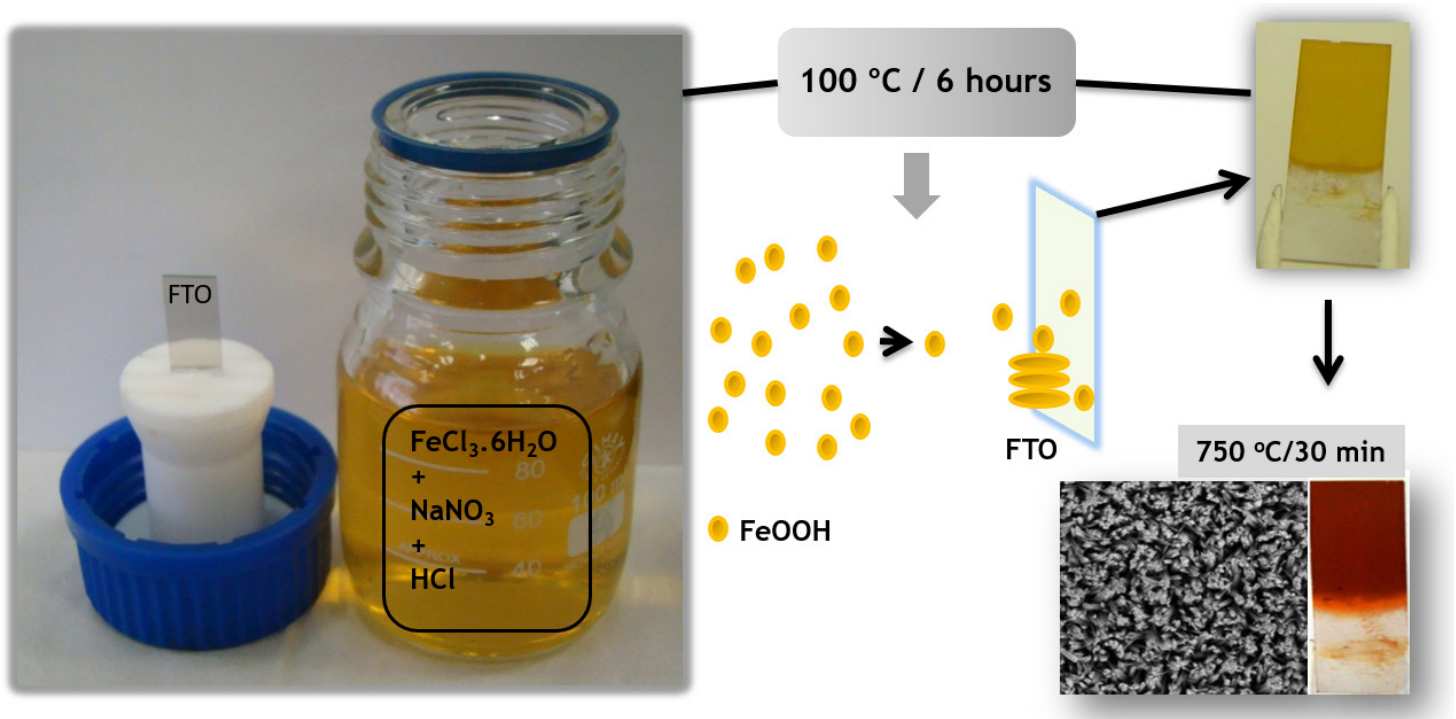

Figure 3 - Schematic representation of PBM process: (left) precursor solution and substrate addition in autoclavable bottle, (top-right) Heating at a temperature below $100^{\circ} \mathrm{C}$ for nucleation process into substrate surface and homogeneous layer deposition, and (lower-right) some cases the desired oxide phase is obtained after annealing process or can be conducted to increase substrate-layer interface. (de Carvalho et al. 2012, Ferraz et al. 2012).

(Figure 4a). In contrast, the sintered spherical electrode morphology in nanometric scale must have a huge number of grain boundaries that may act as recombination sites to decrease the charge separation and transport (Figure 4b). To achieve the ideal hematite performance balance between surface and morphology must be found, as illustrated in Figure 4b. The one-dimensional photoanodes-based morphology might provide the ability to overcome most of the electronic drawbacks of hematite.

Significant progress worldwide has been achieved since this seminal work on hematite photoanode performance and most of the actual records of performance belong to the materials using the hierarchical nanoarchitecture synthesized by the aqueous solution hydrothermal-assisted method (de Carvalho et al. 2012, Ferraz et al. 2012, Ito et al. 2017). The yield of the water oxidation reaction through the hematite was boosted by vertical nanorod morphology and several modifications to synthesis parameters, addition of dopants, surface modification, and high annealing temperatures were proposed over time. Table I illustrates the undoped (UHN) and modified hematite $(\mathrm{MHN})$ photoanode with vertical nanorod morphology synthesized by the PBM method and the influence of those proposed changes on their performance under sunlight-simulated conditions. Although many of the relevant achievements were cited, the authors acknowledge that the selected works on this Table do not represent the entirety of published papers regarding of the PBM method. These compiled works support us in providing an interesting perspective on the state of progress toward improving the OER yield with vertical nanorod hematite

In the case of PEC-based on an undoped hematite nanorod (UHN) electrode, the best performance so far to this date (italics, Table I) is from $1.12-1.48 \mathrm{~mA} \cdot \mathrm{cm}^{-2}$ at $1.23 \mathrm{~V}_{\mathrm{RHE}}$ (RHE, reversible hydrogen reference electrode). The enhancement of the photocurrent response (from $\mu$ to $\mathrm{mA}$ ) was attributed to several changes in the original synthesis parameters (ex. time, temperature, and different precursors), use of different substrates, 
a)
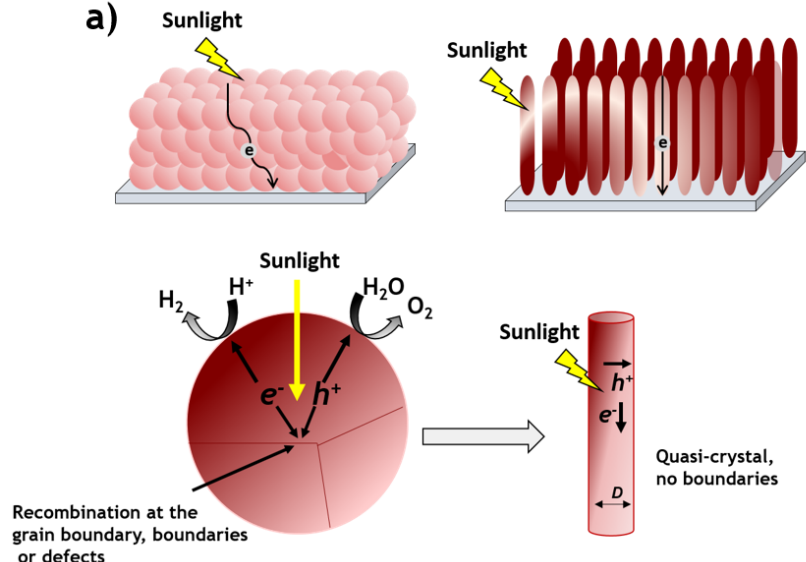

b)

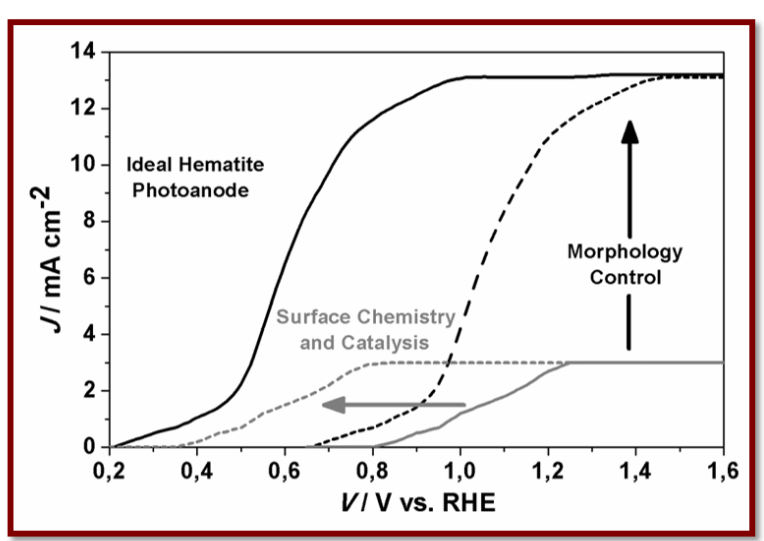

Figure 4 - (a) Solar absorption, charge separation, and chemical reaction at planar and vertical nanostructures grew onto a conductive glass substrate, and (b) Ideal hematite photoanode performance achieved by finding a balance between semiconductor surface and morphology control. Adapted from the reference Lindgren et al. (2002).

and post-annealing treatment at high temperature (700-800 ${ }^{\circ} \mathrm{C}$ ). Among these strategies to boost the hematite photoanode performance, including the UHN electrodes, the treatment at high annealing temperature was a key factor to improve the efficiency of the water oxidation reaction assisted by light. Regardless of the synthetic method used to design the electrodes most of the records in solar photons conversion-to-hydrogen were reached after the photonoanodes were annealed at those range of temperatures. (Wickman et al. 2017, Zhou et al. 2002, Kaouk et al. 2016). In 2011, the influence of temperature on the UHN electrode was investigated and the photocurrent response around $1.24 \mathrm{mAcm}^{-2}$ at $1.23 \mathrm{~V}_{\mathrm{RHE}}$ was observed after annealing at 800 ${ }^{\circ} \mathrm{C}$ (Ling et al. 2011). The authors demonstrated the presence of Sn that comes from the substrate by diffusion and was associated with the UHN electrode performance by X-ray photoelectron spectroscopy (XPS). The percentage of Sn diffusion from the substrate to the hematite layer increased with temperature and enhanced the photoanode up to the limit of TCO electronic conductivity (FTO) and decreased due to this loss and glass distortion. Usually, Sn diffusion from FTO substrate is considered unintentional doping. Sivula et al. (Sivula et al. 2010) studied hematite prepared by a colloidal nanocrystal deposition (CND) process followed by high annealing treatment (at $800{ }^{\circ} \mathrm{C}$ ) and showed for the first time an improvement to the photocurrent density due to unintentional doping that enabled a more efficient charge transport. Besides the unintentional doping, the presence of grain boundaries in polycrystalline hematite nanostructures might limit the incident photon-tocurrent efficiency because thermal annealing can reorient adjacent grains of hematite and passivate grain boundaries to facilitate electronic transport within the hematite network to increase the overall efficiency.

Xi et al. (2013) achieved a similar photocurrent response at $1.23 \mathrm{~V}_{\mathrm{RHE}}$ with a UHN photoanode designed by switching the chemical precursors (adding urea instead of $\mathrm{Na}_{2} \mathrm{NO}_{3} / \mathrm{HCL}$ ) of the PBM method followed by high annealing temperature at $750^{\circ} \mathrm{C}$ for $30 \mathrm{~min}$. Later, Carvalho and Souza (2016) conducted a systematic investigation elucidating the role of synthesis time and annealing temperature on the UHN photoanode performance. They demonstrated that $2 \mathrm{~h}$ was the optimized synthesis condition, enabling a high photocurrent response around $1.12 \mathrm{mAcm}^{-2}$ at $1.23 \mathrm{~V}_{\mathrm{RHE}}$. According to the results, the use of high annealing temperature provides a better UHN surface wettability. The 
TABLE I

Summary of a selection of works based on the significant achievements on PEC performance using undoped (UHN) and modified hematite (MHN) photoanode with vertical nanorod morphology designed by PBM process.

\begin{tabular}{|c|c|c|c|c|c|c|}
\hline $\begin{array}{c}\text { Undoped } \\
\text { haematite } \\
\text { nanorod - UHN }\end{array}$ & $\begin{array}{c}\text { Modified } \\
\text { haematite } \\
\text { nanorod - MHN }\end{array}$ & $\begin{array}{c}\text { Annealing } \\
\text { temperature } \\
\left({ }^{\circ} \mathrm{C}\right)\end{array}$ & $\begin{array}{c}\text { UHN- } J \\
\text { mA.cm at } \\
1.23 \mathrm{~V} \mathrm{vs} \mathrm{RHE}^{-2} \text { RHE }\end{array}$ & $\begin{array}{c}\text { MHN-J } \\
\text { mA.cm }{ }^{-2} \text { at } \\
1.23 \mathrm{~V} \mathrm{vs} \mathrm{RHE}^{2} \text {. }\end{array}$ & year & Reference \\
\hline $\mathrm{X}$ & (N3-dye) & 550 & 0.05 & $<0.15$ & 2000 & (Beermann et al. 2000) \\
\hline $\mathrm{X}$ & ------ & 550 & 0.01 & ------ & 2002 & (Lindgren et al. 2002) \\
\hline $\mathrm{X}$ & $\mathrm{Sn}-\mathrm{HN}$ & 800 & 1.24 & 1.86 & 2011 & (Ling et al. 2011) \\
\hline $\mathrm{X}$ & Ti-HN & $550-750$ & 1.48 & 1.91 & 2012 & (Deng et al. 2012) \\
\hline $\mathrm{X}$ & $\mathrm{Cr}-\mathrm{HN}$ & 750 & 0.03 & 0.05 & 2012 & (Shen et al. 2012) \\
\hline $\mathrm{X}$ & ----- & 390 & 0.9 & ----- & 2012 & (de Carvalho et al. 2012) \\
\hline $\mathrm{X}$ & $\mathrm{N}-\mathrm{HN}$ & 550 & ----- & 1.8 & 2012 & (Ling et al. 2012) \\
\hline $\mathrm{X}$ & $\mathrm{Co}_{3} \mathrm{O}_{4}-\mathrm{HN}$ & $550-800$ & 0.72 & 1.2 & 2012 & (Xi et al. 2012) \\
\hline $\mathrm{X}$ & Ti-HN & 550 & 0.01 & 0.15 & 2012 & (Miao et al. 2012) \\
\hline $\mathrm{X}$ & Sn-HN & 750 & 1.24 & 2.25 & 2013 & (Xi et al. 2013) \\
\hline $\mathrm{X}$ & $\begin{array}{l}\text { Ti-HN with Co } \\
\quad \text { (ions) }\end{array}$ & 650 & 0.3 & 1.2 & 2013 & (Miao et al. 2013) \\
\hline $\mathrm{X}$ & Ti-HN & 750 & 0.45 & 0.66 & 2013 & (Shen et al. 2013b) \\
\hline $\mathrm{X}$ & $\mathrm{Zr}-\mathrm{HN}$ & 750 & 0.03 & 0.33 & 2013 & (Shen et al. 2013a) \\
\hline $\mathrm{X}$ & $\mathrm{Mn}-\mathrm{HN}$ & $550-750$ & 0.45 & 1.4 & 2014 & (Chiam et al. 2014) \\
\hline $\mathrm{X}$ & $\begin{array}{c}\text { HN surface } \\
\text { passivation with } \\
\mathrm{Au}\end{array}$ & 750 & 0.03 & 0.25 & 2014 & (Shen et al. 2014a) \\
\hline $\mathrm{X}$ & $\mathrm{Ag}-\mathrm{HN}$ & 750 & 0.05 & 0.18 & 2014 & (Shen et al. 2014b) \\
\hline $\mathrm{X}$ & $\begin{array}{c}\text { N-HN (layer < } \\
100 \mathrm{~nm})\end{array}$ & 750 & 0.39 & 0.95 & 2015 & (Freitas et al. 2015) \\
\hline $\mathrm{X}$ & Ti-HN & 650 & ----- & 1.9 & 2015 & (Li et al. 2015) \\
\hline $\mathrm{X}$ & ATO-HN & $500-800$ & 0.60 & 2.12 & 2015 & (Wang et al. 2015a) \\
\hline $\mathrm{X}$ & $\mathrm{Nb}-\mathrm{HN}$ & 750 & 0.15 & 0.65 & 2016 & (Fu et al. 2016) \\
\hline $\mathrm{X}$ & $\mathrm{Sn}-\mathrm{HN}$ & 750 & 1.12 & 1.62 & 2016 & (Carvalho and Souza 2016) \\
\hline $\mathrm{X}$ & Sn-HN-Tanden & 650 & 0.78 & 3.12 & 2017 & (John et al. 2017) \\
\hline $\mathrm{X}$ & Cobalt-Sn-HN & 800 & $1.0<$ & 2.2 & 2017 & (Li et al. 2017b) \\
\hline $\mathrm{X}$ & CoPi-TiHN & 800 & 0.9 & 6.0 & 2017 & (Jeon et al. 2017) \\
\hline
\end{tabular}

interaction between semiconductor and electrolytes favored the hole diffusion through the interface to improve the efficiency of the OER. It has been experimentally demonstrated that the electron transport on bare hematite occurs through a bulk process and combining high annealing temperature with the nanorod morphology vertically aligned to the substrate might increase the electron transfer toward the substrate and reduce the recombination rate (Kronawitter et al. 2012). Growing the vertical rod morphology in the [110] direction could increase the photoanode performance further due to a wellknown improvement up to 4 orders of magnitude in the electronic conductivity (reducing the recombination rate). These effects related to a high annealing temperature and hematite performance manufactured by a wide variety of methods, including PBM, has been intensively discussed in the literature (Ling et al. 2011, Annamalai et al. 2015, Li et al. 2017b). Table I summarizes several examples of UHN electrodes with a photocurrent response below $1 \mathrm{mAcm}^{-2}$ at $1.23 \mathrm{~V}_{\mathrm{RHE}}$, where the 
poor performance is due to low electron transport efficiency toward to the substrate or surface traps that compromised the hole diffusion through the solid-liquid interface.

The intentional "doping" or incorporation of Sn over the surface of different hematite morphology (Gonçalves and Leite 2014, Ling and Li 2014), including UHN photoanodes (see values highlighted in bold, Table I), doubled the overall efficiency in comparison with undoped surfaces. Yat Li et al. (Ling et al. 2011) demonstrated that the intentional addition of Sn over the UHN surface combined with high annealing temperature could enhance the photocurrent density from 1.24 to $1.86 \mathrm{mAcm}^{-2}$ at $1.23 \mathrm{~V}_{\mathrm{RHE}}$. When the $\mathrm{Sn}$ addition was performed before the annealing treatment, a significant change in morphology from UHN to coral-like was observed. The SEM images revealed that the coral-like morphology exhibited a smaller feature sizes, which increased the surface area available for chemical reaction and consequently the electrode performance. Additionally, the dynamic of charge by ultrafast spectroscopy was investigated revealing that the hole-electron combination rate within the first picosecond remained high even with Sn-addition. In that study, the improvement observed was attributed to a greater surface area provided by the coral-like morphology that increased the surface availability for chemical reactions. This significant change to morphology by incorporation of $\mathrm{Sn}$ before the annealing treatment has been commonly reported in literature independent of the manufacturing method. Xi et al. (2013) achieved a better photocurrent response by intentional incorporation of $\mathrm{Sn}$ over the $\mathrm{HN}$ layer followed by annealing at $750{ }^{\circ} \mathrm{C}$ for 30 min without a substantial change in morphology (values illustrated in Table I). The pronounced improvement was associated with the formation of a $\mathrm{Fe}_{\mathrm{x}} \mathrm{Sn}_{1-\mathrm{x}} \mathrm{O}_{4}$ layer that was passivated, which possibly reduced the recombination rate at the electrode-electrolyte interface. A shift of $100 \mathrm{mV}$ on the onset potential toward a cathodic direction was observed and related to the Sn addition. This may lead the photoanode to oxidize water induced by light and demanding a higher value of external bias. The causes behind this cathodic shift of the onset potential remain unclear.

Similarly, Carvalho and Souza (2016) studied the incorporation of Sn over the HN surface followed by high annealing temperature and did not observe significant alteration to the vertical rod morphology (as exemplified in Figure 5). The preserved rod shape exhibited a slight reduction in the rod length and diameter due to the $\mathrm{Sn}$ addition. According to the literature and our investigations, the addition of Sn over the HN surface probably segregated at the rod surface by suppressing the crystal growth. The SEM and TEM images revealed that a slight layer was formed over the rod surface (also observed by $\mathrm{Xi}$ et al. 2013). However, the chemical composition evaluated by energy dispersive spectroscopy (EDS) coupled to TEM showed the formation of an $\mathrm{SnO}_{2}$ phase instead of $\mathrm{Fe}_{\mathrm{x}} \mathrm{Sn}_{1-\mathrm{x}} \mathrm{O}_{4}$. The impedance spectroscopy data analyzed by a Mott-Schottky plot showed no significant changes to the donor charge density, which may have excluded the improvement to the electronic conductivity. By performing contact angle measurement before and after the $\mathrm{Sn}$ incorporation it was found that pronounced enhancement of the semiconductorelectrolyte interaction might favor increased hole collection by this quasi-super hydrophilic surface.

The other modifiers combined with annealing treatment as highlighted in Table I have also improved the HN photoanode performance, but in some cases the photocurrent density remained modest in comparison with Sn. Over last two years, the incorporation of $\mathrm{Ti}$ over $\mathrm{HN}$ has gained attention due to important achievements regarding the performance and comprehension of this impurity within the system by experimental and theoretical investigation. Choi et al. in the current year, optimized the addition of Ti over the 
$\mathrm{HN}$ surface and established a new performance record by achieving $6 \mathrm{~mA} . \mathrm{cm}^{-2}$ at $1.23 \mathrm{~V}_{\mathrm{RHE}}$ and long-term durability on the field. The sample preparation consisted of a complex procedure that involved the Ti addition over HN photoanode followed by a successive annealing treatment at different temperatures and atmosphere. Afterward, the deposition of cobalt phosphate as a cocatalyst over the Ti-HN followed by annealing treatment at $350{ }^{\circ} \mathrm{C}$ under hydrogen gas flux (Jeon et al. 2017) ended the fabrication process. This is the highest photocurrent response reported so far of any synthetic method or modifier. This brief review summarizes the substantial progress including the new record in the field by combining the columnar morphology, high annealing temperature, and metal transition element incorporation toward the deeper understanding, control, and optimization to achieve higher performance. Much investigation remains to make the earth-abundant mineral, hematite, optimal for PEC application.

\section{CONCLUSIONS}

This brief review summarizes the latest advances on columnar hematite electrodes designed by a
PBM process including the recent record on the field. The columnar morphology might overcome most of the significant drawbacks of this earthabundant material for developing low-cost and efficient PEC devices. The current discussion and recent achievements support our assertion that the columnar morphology and preferential crystal orientation at specific direction onto the substrate is fundamental to fabricating an active bare hematite photoanode for sunlight-driven OER. In the case of cocatalyst incorporation (ex.: Ti and $\mathrm{Sn}$ ) over the HN electrode surface, which are currently responsible for the highest performance on hematite, additional parameters are relevant besides columnar morphology. However, it is clear that combining columnar morphology, high annealing temperature, and surface changes by incorporating cocatalysts might lead to a pronounced reduction in bulk and surface traps. The suppression of those defects might decrease the hole-electron recombination rate to favor a more efficient OER. Those proposed strategies may lead to: (i) an improved solid-solid interface by high annealing temperature, which will facilitate the electron transfer through the back contact; and (ii) solid-

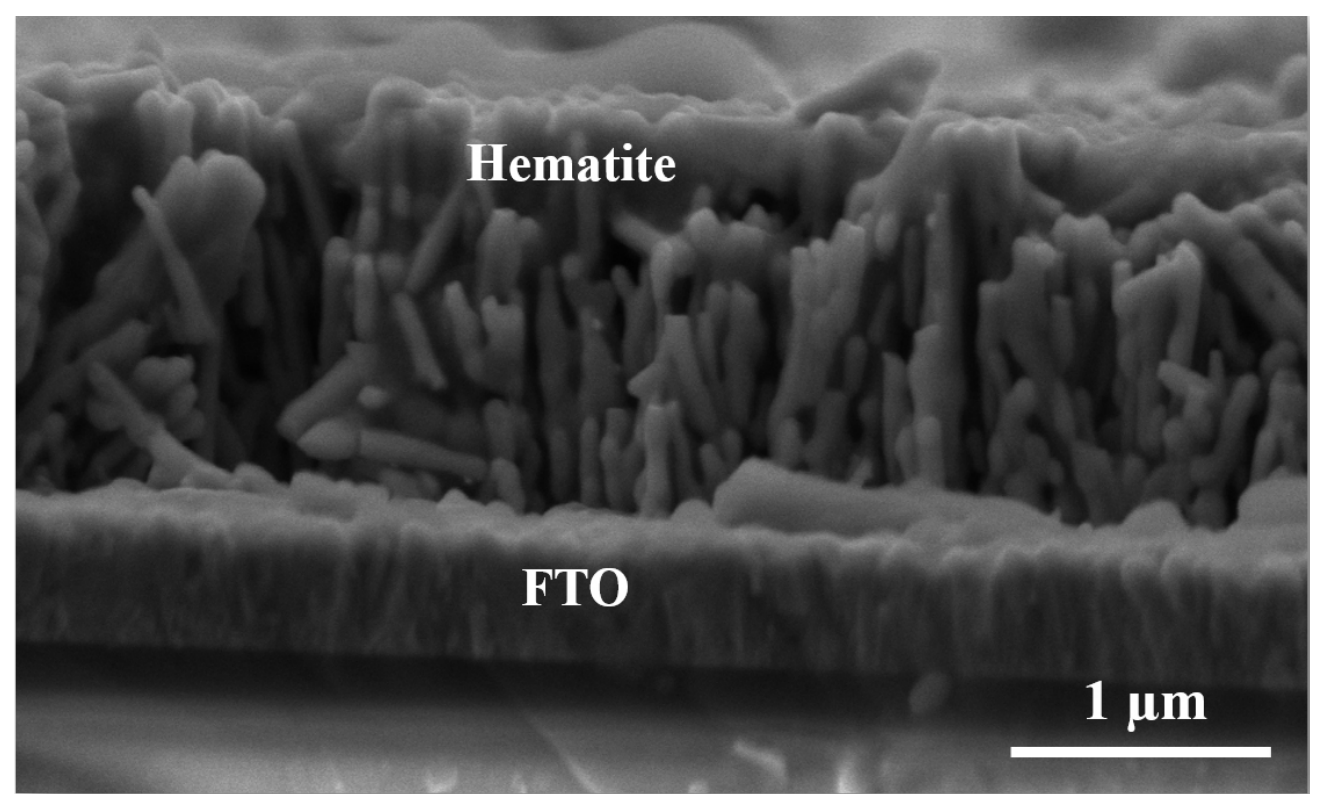

Figure 5 - Scanning electron microscopy (SEM) image of the cleaved Sn-hematite film. 
liquid interface associated with the incorporation of cocatalyst that will passivate the semiconductor surface to increase the hole diffusion and enable chemical reactions. Even though the development of PEC devices is fundamentally based on a polycrystalline semiconductor (hematite), in contrast with single crystal commercial technologies, we learned that high performance can be achieved by combining simple strategies to minimize the defects or recombination sites. By designing nanostructure with minimum grain boundaries and certain crystal orientation, such as the hierarchical nanoarchitecture discussed in this brief review, an efficient photoanode can be developed. Although substantial progress over this last 35 years was achieved for the use of hematite, including materials prepared by the PBM method, there is room for optimization and fundamental investigation because catalytic and electronic mechanisms remain unsolved. To directly convert and store solar energy as chemical energy (hydrogen and oxygen) by using seawater and sustainable sunlight irradiation will be a most economical approach to provide clean and sustainable energy that supplies the global demand.

\section{ACKNOWLEDGMENTS}

The authors acknowledge the financial support from the Brazilian agencies Fundação de Amparo à Pesquisa do Estado de São Paulo (FAPESP, proc. 2016/02157-2 and 2011/19924-2), Coordenação de Aperfeiçoamento de Pessoal de Nível Superior (CAPES), CEM-UFABC, and CDMF (grant 2013/07296-2).

\section{REFERENCES}

ANNAMALAI A, KANNAN AG, LEE SY, KIM D-W, CHOI SH AND JANG JS. 2015. Role of graphene oxide as a sacrificial interlayer for enhanced photoelectrochemical water oxidation of hematite nanorods. J Phys Chem C 119: 19996-20002.
BAILLY G, ROSSIGNOL JRM, DE FONSECA B, PRIBETICH P AND STUERGA D. 2016. Microwave gas sensing with hematite: Shape effect on ammonia detection using pseudocubic, rhombohedral, and spindlelike particles. ACS Sensors 1: 656-662.

BARD AJ AND FOX MA. 1995. Artificial photosynthesis: solar splitting of water to hydrogen and oxygen. Acc Chem Res 28: 141-145.

BARROSO M, MESA CA, PENDLEBURY SR, COWAN AJ, HISATOMI T, SIVULA K, GRÄTZEL M, KLUG DR AND DURRANT JR. 2012. Dynamics of photogenerated holes in surface modified $\alpha$-Fe2O3 photoanodes for solar water splitting. PNAS 109: 15640-15645.

BEERMANN N, VAYSSIERES L, LINDQUIST SE AND HAGFELDT A. 2000. Photoelectrochemical studies of oriented nanorod thin films of hematite. J Electrochem Soc 147: 2456-2461.

BENJELLOUN D, BONNET J-P, DOUMERC JP, LAUNAY J-C, ONILLON M AND HAGENMULLER P. 1984. Anisotropie des proprietes electriques de l'oxyde de fer Fe2O3 $\alpha$. Mater Chem Phys 10: 503-518.

BERTOLUZZI L AND BISQUERT J. 2012. Equivalent circuit of electrons and holes in thin semiconductor films for photoelectrochemical water splitting applications. J Phys Chem Lett 3: 2517-2522.

BOLTON JR AND HALL DO. 1979. Photochemical conversion and storage of solar energy. Annu Rev Energy 4: 353-401.

BORA DK, BRAUN A AND CONSTABLE EC. 2013. "In rust we trust". Hematite-the prospective inorganic backbone for artificial photosynthesis. Energy Environ Sci 6: 407425.

CARVALHO WM AND SOUZA FL. 2016. Hematite Surface Activation by Chemical Addition of Tin Oxide Layer. ChemPhysChem 17: 2710-2717.

CHIAM SY, KUMAR MH, BASSI PS, SENG HL, BARBER J AND WONG LH. 2014. Improving the efficiency of hematite nanorods for photoelectrochemical water splitting by doping with manganese. ACS Appl Mater Interfaces 6: 5852-5859.

CHO IS, HAN HS, LOGAR M, PARK J AND ZHENG X. 2016. Solar Water Splitting: Enhancing Low-Bias Performance of Hematite Photoanodes for Solar Water Splitting by Simultaneous Reduction of Bulk, Interface, and Surface Recombination Pathways (Adv. Energy Mater. 4/2016). Adv Energy Mater 6.

CHOI J, SUDHAGAR P, KIM JH, KWON J, KIM J, TERASHIMA C, FUJISHIMA A, SONG T AND PAIK U. 2017. WO 3/W: BiVO 4/BiVO 4 graded photoabsorber electrode for enhanced photoelectrocatalytic solar light driven water oxidation. Phys Chem Chem Phys 19: 46484655 . 
DE CARVALHO VAN, LUZ RADS, LIMA BH, CRESPILHO FN, LEITE ER AND SOUZA FL. 2012. Highly oriented hematite nanorods arrays for photoelectrochemical water splitting. J Power Sources 205: 525-529.

DE CARVALHO WM AND SOUZA FL. 2014. Recent advances on solar water splitting using hematite nanorod film produced by purpose-built material methods. J Mater Res 29: 16-28.

DENG J, ZHONG J, PU A, ZHANG D, LI M, SUN X AND LEE S-T. 2012. Ti-doped hematite nanostructures for solar water splitting with high efficiency. J Appl Phys 112: 084312.

DIAS P, LOPES T, MEDA L, ANDRADE L AND MENDES A. 2016. Photoelectrochemical water splitting using WO 3 photoanodes: the substrate and temperature roles. Phys Chem Chem Phys 18: 5232-5243.

DURET A AND GRÄTZEL M. 2005. Visible light-induced water oxidation on mesoscopic $\alpha$-Fe2O3 films made by ultrasonic spray pyrolysis. J Phys Chem B 109: 1718417191.

EGGLESTON CM. 2008. Toward new uses for hematite. Science 320: 184-185.

FERRAZ LC, CARVALHO JR WM, CRIADO D AND SOUZA FL. 2012. Vertically oriented iron oxide films produced by hydrothermal process: effect of thermal treatment on the physical chemical properties. ACS Appl Mater Interfaces 4: 5515-5523.

FREITAS AL, CARVALHO WM AND SOUZA FL. 2015. Enhanced water oxidation efficiency of hematite thin films by oxygen-deficient atmosphere. J Mater Res 30: 3595 3604.

FU Y, DONG CL, LEE WY, CHEN J, GUO P, ZHAO L AND SHEN S. 2016. Nb-Doped Hematite Nanorods for Efficient Solar Water Splitting: Electronic Structure Evolution versus Morphology Alteration. ChemNanoMat 2: 704-711.

FUJISHIMA A AND HONDA K. 1972. Electrochemical Photolysis of Water at a Semiconductor Electrode. Nature 238: 37-38.

GONÇALVES RH AND LEITE ER. 2014. The colloidal nanocrystal deposition process: an advanced method to prepare high performance hematite photoanodes for water splitting. Energy Environ Sci 7: 2250-2254.

GONCALVES RH, LEITE LD AND LEITE ER. 2012. Colloidal WO3 nanowires as a versatile route to prepare a photoanode for solar water splitting. ChemSusChem 5: 2341-2347.

GONÇALVES RH, LIMA BH AND LEITE ER. 2011. Magnetite colloidal nanocrystals: a facile pathway to prepare mesoporous hematite thin films for photoelectrochemical water splitting. J Am Chem Soc 133: 6012-6019.
GRAETZEL M. 1981. Artificial photosynthesis: water cleavage into hydrogen and oxygen by visible light. Acc Chem Res14: 376-384.

HAGFELDT A AND GRAETZEL M. 1995. Light-induced redox reactions in nanocrystalline systems. Chem Rev 95: 49-68.

HAMANN TW. 2012. Splitting water with rust: hematite photoelectrochemistry. Dalton Trans 41: 7830-7834.

HARDEE KL AND BARD AJ. 1976. Semiconductor electrodes V. The application of chemically vapor deposited iron oxide films to photosensitized electrolysis. J Electrochem Soc 123: 1024-1026.

HISATOMI T, KUBOTA J AND DOMEN K. 2014. Recent advances in semiconductors for photocatalytic and photoelectrochemical water splitting. Chem Soc Rev 43: 7520-7535.

ITO NM, CARVALHO-JR WM, MUCHE DNF, DALPIAN G, CASTRO RH AND SOUZA FL. 2017. High temperature activation of hematite nanorods for sunlight driven water oxidation reaction. Phys Chem Chem Phys 19: 25025 25032.

JEON TH, MOON GH, PARK H AND CHOI W. 2017. Ultraefficient and durable photoelectrochemical water oxidation using elaborately designed hematite nanorod arrays. Nano Energy 39: 211-218.

JOHN RA, BOIX PP, YI C, SHI C, SCOTT M, VELDHUIS SA, MINOR AM, ZAKEERUDDIN SM, WONG LH AND GRÄTZEL M. 2017. Atomically Altered Hematite for Highly Efficient Perovskite Tandem Water-Splitting Devices. ChemSusChem 10: 2449-2456.

KAFIZAS A, FRANCÀS L, SOTELO-VAZQUEZ C, LING M, LI Y, GLOVER E, MCCAFFERTY L, BLACKMAN C, DARR J AND PARKIN I. 2017. Optimizing the Activity of Nanoneedle Structured WO3 Photoanodes for Solar Water Splitting: Direct Synthesis via Chemical Vapor Deposition. J Phys Chem C 121: 5983-5993.

KAOUK A, RUOKO TP, PYEON M, GÖNÜLLÜ Y, KAUNISTO K, LEMMETYINEN H AND MATHUR S. 2016. High Water-Splitting Efficiency through Intentional In and Sn Codoping in Hematite Photoanodes. J Phys Chem C 120: 28345-28353.

KENNEDY JH AND FRESE KW. 1978. Photooxidation of water at $\alpha-\mathrm{Fe} 2$ O 3 electrodes. J Electrochem Soc 125: 709-714.

KLAHR BM AND HAMANN TW. 2011. Current and voltage limiting processes in thin film hematite electrodes. J Phys Chem C 115: 8393-8399.

KMENT S, RIBONI F, PAUSOVA S, WANG L, WANG L, HAN H, HUBICKA Z, KRYSA J, SCHMUKI P AND ZBORIL R. 2017. Photoanodes based on TiO 2 and $\alpha$-Fe 2 O 3 for solar water splitting-superior role of $1 \mathrm{D}$ nanoarchitectures and of combined heterostructures. Chem Soc Rev 46: 3716-3769. 
KRONAWITTER CX, VAYSSIERES L, SHEN S, GUO L, WHEELER DA, ZHANG JZ, ANTOUN BR AND MAO SS. 2011. A perspective on solar-driven water splitting with all-oxide hetero-nanostructures. Energy Environ Sci 4: 3889-3899.

KRONAWITTER C, ZEGKINOGLOU I, ROGERO C, GUO J-H, MAO S, HIMPSEL F AND VAYSSIERES L. 2012. On the interfacial electronic structure origin of efficiency enhancement in hematite photoanodes. J Phys Chem C 116: $22780-22785$.

KUDO A AND MISEKI Y. 2009. Heterogeneous photocatalyst materials for water splitting. Chem Soc Rev 38: 253-278.

LANDMAN A, DOTAN H, SHTER GE, WULLENKORD M, HOUAIJIA A, MALJUSCH A, GRADER GS AND ROTHSCHILD A. 2017. Photoelectrochemical water splitting in separate oxygen and hydrogen cells. Nat Mater 16: 646-651.

LAVINA B AND MENG Y. 2015. Unraveling the complexity of iron oxides at high pressure and temperature: Synthesis of Fe 5 O 6. Sci Adv 1: e1400260.

LEWIS NS AND NOCERA DG. 2006. Powering the planet: Chemical challenges in solar energy utilization. PNAS 103: 15729-15735.

LI H, ZHAO F, ZHANG J, LUO L, XIAO X, HUANG Y, JI H AND TONG Y. 2017a. A gC 3 N 4/WO 3 photoanode with exceptional ability for photoelectrochemical water splitting. Materials Chemistry Frontiers 1: 338-342.

LI M, YANG Y, LING Y, QIU W, WANG F, LIU T, SONG Y, LIU X, FANG P AND TONG Y. 2017b. Morphology and Doping Engineering of Sn-Doped Hematite Nanowire Photoanodes. Nano Lett 17: 2490-2495.

LI X, BASSI PS, BOIX PP, FANG Y AND WONG LH. 2015. Revealing the role of $\mathrm{TiO} 2$ surface treatment of hematite nanorods photoanodes for solar water splitting. ACS Appl Mater Interfaces 7: 16960-16966.

LINDGREN T, WANG H, BEERMANN N, VAYSSIERES L, HAGFELDT A AND LINDQUIST S-E. 2002. Aqueous photoelectrochemistry of hematite nanorod array. Sol Energy Mater Sol Cells 71: 231-243.

LING Y AND LI Y. 2014. Review of Sn-Doped Hematite Nanostructures for Photoelectrochemical Water Splitting. Part Part Syst Charact 31: 1113-1121.

LING Y, WANG G, REDDY J, WANG C, ZHANG JZ AND LI Y. 2012. The influence of oxygen content on the thermal activation of hematite nanowires. Angew Chem Int Ed 51: 4074-4079.

LING Y, WANG G, WHEELER DA, ZHANG JZ AND LI Y. 2011. Sn-doped hematite nanostructures for photoelectrochemical water splitting. Nano Lett 11: 21192125.

LIU R, LIN Y, CHOU LY, SHEEHAN SW, HE W, ZHANG F, HOU HJ AND WANG D. 2011. Water Splitting by Tungsten Oxide Prepared by Atomic Layer Deposition and Decorated with an Oxygen-Evolving Catalyst. Angew Chem 123: 519-522.

LOTHIAN G. 1963. Beer's law and its use in analysis. A review. Analyst 88: 678-685.

MAVROIDES J, KAFALAS J AND KOLESAR D. 1976. Photoelectrolysis of water in cells with $\mathrm{SrTiO} 3$ anodes. Appl Phys Lett 28: 241-243.

MIAO C, JI S, XU G, LIU G, ZHANG L AND YE C. 2012. Micro-nano-structured $\mathrm{Fe} 2 \mathrm{O} 3$ : Ti/ZnFe2O4 heterojunction films for water oxidation. ACS Appl Mater Interfaces 4: 4428-4433.

MIAO C, SHI T, XU G, JI S AND YE C. 2013. Photocurrent enhancement for Ti-doped $\mathrm{Fe} 2 \mathrm{O} 3$ thin film photoanodes by an in situ solid-state reaction method. ACS Appl Mater Interfaces 5: 1310-1316.

MURPHY A, BARNES P, RANDENIYA L, PLUMB I, GREY I, HORNE M AND GLASSCOCK J. 2006. Efficiency of solar water splitting using semiconductor electrodes. Int J Hydrog Energy 31: 1999-2017.

NAVROTSKY A, MAZEINA L AND MAJZLAN J. 2008. Size-driven structural and thermodynamic complexity in iron oxides. Science 319: 1635-1638.

NELLIST MR, LASKOWSKI FA, LIN F, MILLS TJ AND BOETTCHER SW. 2016. Semiconductor-electrocatalyst interfaces: theory, experiment, and applications in photoelectrochemical water splitting. Acc Chem Res 49: 733-740.

NOZIK AJ. 1978. Photoelectrochemistry: applications to solar energy conversion. Anny Rev Phys Chem 29: 189-222.

NOZIK AJ AND MEMMING R. 1996. Physical chemistry of semiconductor- liquid interfaces. J Phys Chem 100: 13061-13078.

PAILHÉ N, WATtiAUX A, GAUDON M AND DEMOURGUES A. 2008. Impact of structural features on pigment properties of $\alpha$-Fe 2 O 3 haematite. J Solid State Chem 181: 2697-2704.

PARK Y, MCDONALD KJ AND CHOI K-S. 2013. Progress in bismuth vanadate photoanodes for use in solar water oxidation. Chem Soc Rev 42: 2321-2337.

PAULING L AND HENDRICKS SB. 1925. The crystal structures of hematite and corundum. J Am Chem Soc 47: 781-790.

PINHEIRO AN, FIRMIANO EG, RABELO AC, DALMASCHIO CJ AND LEITE ER. 2014. Revisiting SrTiO 3 as a photoanode for water splitting: development of thin films with enhanced charge separation under standard solar irradiation. Rsc Advances 4: 2029-2036.

QUINN RK, NASBY R AND BAUGHMAN R. 1976. Photoassisted electrolysis of water using single crystal $\alpha-\mathrm{Fe} 2 \mathrm{O} 3$ anodes. Mater Res Bull 11: 1011-1017.

ROSSO KM, SMITH DM AND DUPUIS M. 2003. An ab initio model of electron transport in hematite ( $\alpha$-Fe 2 O 3) basal planes. J Chem Phys 118: 6455-6466. 
SANTATO C, ODZIEMKOWSKI M, ULMANN M AND AUGUSTYNSKI J. 2001. Crystallographically oriented mesoporous WO3 films: synthesis, characterization, and applications. J Am Chem Soc 123: 10639-10649.

SAYAMA K, NOMURA A, ZOU Z, ABE R, ABE Y AND ARAKAWA H. 2003. Photoelectrochemical decomposition of water on nanocrystalline BiVO 4 film electrodes under visible light. Chem Commun 23: 2908-2909.

SHEN S. 2014. Toward efficient solar water splitting over hematite photoelectrodes. J Mater Res 29: 29-46.

SHEN S, GUO P, WHEELER DA, JIANG J, LINDLEY SA, KRONAWITTER CX, ZHANG JZ, GUO L AND MAO SS. 2013a. Physical and photoelectrochemical properties of Zr-doped hematite nanorod arrays. Nanoscale 5: 98679874.

SHEN S, JIANG J, GUO P, KRONAWITTER CX, MAO SS AND GUO L. 2012. Effect of $\mathrm{Cr}$ doping on the photoelectrochemical performance of hematite nanorod photoanodes. Nano Energy 1: 732-741.

SHEN S, KRONAWITTER CX, WHEELER DA, GUO P, LINDLEY SA, JIANG J, ZHANG JZ, GUO L AND MAO SS. 2013b. Physical and photoelectrochemical characterization of Ti-doped hematite photoanodes prepared by solution growth. J Mater Chem A 1: 1449814506

SHEN S, LI M, GUO L, JIANG J AND MAO SS. 2014a. Surface passivation of undoped hematite nanorod arrays via aqueous solution growth for improved photoelectrochemical water splitting. J Colloid Interface Sci 427: 20-24.

SHEN S, ZHOU J, DONG CL, HU Y, TSENG EN, GUO P, GUO L AND MAO SS. 2014b. Surface Engineered Doping of Hematite Nanorod Arrays for Improved Photoelectrochemical Water Splitting. Sci Rep 4: 6627.

SHEN S, ZHOU J, DONG CL, HU Y, TSENG EN, GUO P, GUO L AND MAO SS. 2014c. Surface engineered doping of hematite nanorod arrays for improved photoelectrochemical water splitting. Sci Rep 4: 6627.

SHINAR R AND KENNEDY JH. 1982. Photoactivity of doped $\alpha$ Fe2O3 electrodes. Sol Energy Mater 6: 323-335.

SHINDE PS, ANNAMALAI A, KIM JH, CHOI SH, LEE JS AND JANG JS. 2015. Exploiting the dynamic Sn diffusion from deformation of FTO to boost the photocurrent performance of hematite photoanodes. Sol Energy Mater Sol Cells 141: 71-79.

SHINDE PS, CHOI SH, KIM Y, RYU J AND JANG JS. 2016. Onset potential behavior in $\alpha$-Fe 2 O 3 photoanodes: the influence of surface and diffusion Sn doping on the surface states. Phys Chem Chem Phys 18: 2495-2509.

SIVULA K. 2013. Metal oxide photoelectrodes for solar fuel production, surface traps, and catalysis. J Phys Chem Lett 4: 1624-1633.
SIVULA K, LE FORMAL F AND GRÄTZEL M. 2011. Solar water splitting: progress using hematite $(\alpha-\mathrm{Fe} 2 \mathrm{O} 3)$ photoelectrodes. ChemSusChem 4: 432-449.

SIVULA K AND VAN DE KROL R. 2016. Semiconducting materials for photoelectrochemical energy conversion. Nat Rev Mater 1: 15010.

SIVULA K, ZBORIL R, LE FORMAL F, ROBERT R, WEIDENKAFF A, TUCEK J, FRYDRYCH J AND GRATZEL M. 2010. Photoelectrochemical water splitting with mesoporous hematite prepared by a solution-based colloidal approach. J Am Chem Soc 132: 7436-7444.

SMITH R AND FULLER M. 1967. Alpha-hematite: stable remanence and memory. Science 156: 1130-1133.

SOARES MR, GONÇALVES RH, NOGUEIRA IC, BETTINI J, CHIQUITO AJ AND LEITE ER. 2016. Understanding the fundamental electrical and photoelectrochemical behavior of a hematite photoanode. Phys Chem Chem Phys 18: 21780-21788.

SOUZA FL, LOPES KP, LONGO E AND LEITE ER. 2009a.

The influence of the film thickness of nanostructured $\alpha$-Fe 2 O 3 on water photooxidation. Phys Chem Chem Phys 11: 1215-1219.

SOUZA FL, LOPES KP, NASCENTE PA AND LEITE ER. 2009b. Nanostructured hematite thin films produced by spin-coating deposition solution: Application in water splitting. Sol Energy Mater Sol Cells 93: 362-368.

STEIER L, HERRAIZ-CARDONA I, GIMENEZ S, FABREGAT-SANTIAGO F, BISQUERT J, TILLEY SD AND GRÄTZEL M. 2014. Understanding the role of underlayers and overlayers in thin film hematite photoanodes. Adv Funct Mater 24: 7681-7688.

SU J AND VAYSSIERES L. 2016. A Place in the Sun for Artificial Photosynthesis? ACS Energy Lett 1: 121-135.

TAMIRAT AG, RICK J, DUBALEAA, SU WN AND HWANG BJ. 2016. Using hematite for photoelectrochemical water splitting: a review of current progress and challenges. Nanoscale Horiz 1: 243-267.

TRASATTI S. 1980. Electrocatalysis by oxides-attempt at a unifying approach. J Electroanal Chem Interfacial Electrochem 111: 125-131.

TUČEK J, MACHALA L, ONO S, NAMAI A, YOSHIKIYO M, IMOTO K, TOKORO H, OHKOSHI S-I AND ZBOŘIL R. 2015. Zeta-Fe2O3-A new stable polymorph in iron (III) oxide family. Sci Rep 5: 15091.

VAYSSIERES L, GUO J AND NORDGREN J. 2000. MRS Proceedings. Cambridge Univ Press, 635, C7, 8 p.

VAYSSIERES L, BEERMANN N, LINDQUIST S-E AND HAGFELDT A. 2001a. Controlled aqueous chemical growth of oriented three-dimensional crystalline nanorod arrays: Application to iron (III) oxides. Chem Mater 13: 233-235.

VAYSSIERES L, KEIS K, LINDQUIST S-E AND HAGFELDT A. 2001b. Purpose-built anisotropic metal 
oxide material: 3D highly oriented microrod array of $\mathrm{ZnO}$. J Phys Chem B 105: 3350-3352.

VAYSSIERES L. 2004. On the design of advanced metal oxide nanomaterials. Int J Nanotechnol 1: 1-41.

WALTER MG, WARREN EL, MCKONE JR, BOETTCHER SW, MI Q, SANTORI EA AND LEWIS NS. 2010. Solar water splitting cells. Chem Rev 110: 6446-6473.

WANG D, ZHANG Y, PENG C, WANG J, HUANG Q, SU S, WANG L, HUANG W AND FAN C. 2015a. Crystallinity Engineering of Hematite Nanorods for High-Efficiency Photoelectrochemical Water Splitting. Adv Sci 2(4): 1500005.

WANG T, HUNG HT, WANG W, LI PC, HSIEH YK, DONG Y AND WANG CF. 2015b. Application of surface complexation modeling on modification of hematite surface with cobalt cocatalysts: a potential tool for preparing homogeneously distributed catalysts. RSC Adv 5: 67700-67705.

WARREN SC, VOÏTCHOVSKY K, DOTAN H, LEROY CM, CORNUZ M, STELLACCI F, HÉBERT C, ROTHSCHILD A AND GRÄTZEL M. 2013. Identifying champion nanostructures for solar water-splitting. Nat Mater 12: 842-849.

WICKMAN B, FANTA AB, BURROWS A, HELLMAN A, WAGNER JB AND IANDOLO B. 2017. Iron Oxide Films Prepared by Rapid Thermal Processing for Solar Energy Conversion. Sci Rep 7: 40500.

XAVIER AM, FERREIRA FF AND SOUZA FL. 2014. Morphological and structural evolution from akaganeite to hematite of nanorods monitored by ex situ synchrotron X-ray powder diffraction. RSC Adv 4: 17753-17759.

XI L, CHIAM SY, MAK WF, TRAN PD, BARBER J, LOO SCJ AND WONG LH. 2013. A novel strategy for surface treatment on hematite photoanode for efficient water oxidation. Chem Sci 4: 164-169.

XI L, TRAN PD, CHIAM SY, BASSI PS, MAK WF, MULMUDI HK, BATABYAL SK, BARBER J, LOO JSC AND WONG LH. 2012. Co3O4-decorated hematite nanorods as an effective photoanode for solar water oxidation. J Phys Chem C 116: 13884-13889.

YANG L, ZHOU H, FAN T AND ZHANG D. 2014. Semiconductor photocatalysts for water oxidation: current status and challenges. Phys Chem Chem Phys 16: 68106826.

YOUNG KM, KLAHR BM, ZANDI O AND HAMANN TW. 2013. Photocatalytic water oxidation with hematite electrodes. Catal Sci Technol 3: 1660-1671.

ZANDI O AND HAMANN TW. 2015. The potential versus current state of water splitting with hematite. Phys Chem Chem Phys 17: 22485-22503.

ZHANG K, RAVISHANKAR S, MA M, VEERAPPAN G, BISQUERT J, FABREGAT-SANTIAGO F AND PARK JH. 2017. Overcoming Charge Collection Limitation at Solid/Liquid Interface by a Controllable Crystal Deficient Overlayer. Adv Energy Mater 7.

ZHOU F, KOTRU S AND PANDEY R. 2002. Pulsed laserdeposited ilmenite-hematite films for application in hightemperature electronics. Thin Solid Films 408: 33-36. 